\title{
Comparison of Various Incision Techniques in Abdominal Surgery
}

\author{
Authors \\ Dr Nisar Ahmad Ansari ${ }^{1}$, Dr Osman Musa Hingora ${ }^{2 *}$, Dr R P Singh ${ }^{3}$ \\ ${ }^{1}$ Associate Professor, ELMC \& H, Lucknow India \\ Email: nisy1972nisy@yahoo.co.in \\ ${ }^{2}$ Professor, ELMC \& H, Lucknow India \\ ${ }^{3}$ JR III, ELMC \& H, Lucknow India \\ Eras Lucknow medical College \& Hospital, Sarfarazganj, Lucknow-226003 \\ *Corresponding Author \\ Dr Osman Musa Hingora
}

Professor \& Head, Eras Lucknow medical College \& Hospital, Sarfarazganj, Lucknow, India

Email: drosman112@yahoo.com

\begin{abstract}
Surgical incisions are usually made with scalpel but usually results in skin bleeding which obscure the operating field. Other alternative in making surgical incision is diathermy. Usually skin incision by diathermy is avoided due to fear of deep burn and scarring when compared with scalpel incision, which create a clean incised wound with minimal tissue destruction. But diathermy in skin incisions decreases bleeding with less incision time. This study compared the complication and effectiveness of various techniques of making skin incisions in an abdominal surgical procedure in 105 patients in age group of 20-60 years. Patients were divided into 3 groups: A: Incision by sharp needle electrode only. B: Incision to reticular dermis with scalpel blade then further incision deep to the peritoneum with sharp needle electrode. C: Incision by conventional scalpel only.

Result: There was no difference between group $A$, group $B$ and group $C$ regarding age, sex and weight $(p>0.05)$. The incision bleeding was less in group A (statistically non-significant, $p>0.05)$. There were more inflamed wounds in group $A$ on $3 r d$ day as compared to group $B$ and group $C$ (statistically significant $p<0.05$ ). The postoperative complications and hospital stay were less in group $C$ compared to group $A$ and group B (statistically non significant $p>0.05$ ). There was no difference in group A, group B and group $C$ regarding cosmetic appearance after three months.

Conclusion: Study suggested that scalpel blade is superior to electro diathermy for making surgical incisions.

Keywords: Diathermy, Incision.
\end{abstract}

\section{Introduction}

The choice of incision is mainly dependent on the area that needs to be exposed, the elective or emergency nature of the operation and the surgeon's personal preference. However, type of incision may have a profound influence on the occurrence of postoperative wound complications. Conventionally, scalpels have been used to make 
surgical incisions. However, since its introduction in the early part of the 20th century, electro surgery has been widely used as an alternative tool for creating incisions. The use of electricity in medicine dates back to the $16^{\text {th }}$ century when William Gilbert, physician to Queen Elizabeth, performed experiments with magnetism and electricity. ${ }^{1}$ The potential benefits of electro surgery include reduced blood loss, dry and rapid separation of the tissue, and a possible decrease in the risk of accidental injury caused by the scalpel to operative personnel. ${ }^{2}$ There are, however, concerns about use of electrosurgical knife as it was reported to be one of several variables contributing to postoperative abdominal wall incision infection, poor wound healing and adhesion formation. ${ }^{4}$ Traditionally, surgical incisions are made with surgical blade. This method of making incisions in an old method and surgeons are always in search of some new methods for making surgical incisions because incisions made by scalpel are supposed to be more bloody and painful. To overcome such problem lasers and cavitron electronic surgical aspirator (SUSA) have been used by some surgeons. But these instruments are more expensive. In this race electric diathermy have used by some surgeons for making incisions. This instrument is easily available in every operation theatre (O.T.) but because of fear of tissue damage leading to poor wound healing and infection. Very few surgeons have been using it for this purpose. The fear was to some extent resolved by Dixon and Watkin ${ }^{3}$ in a study comparing conventions scalpel and electro diathermy incision.

In the recent prospective randomized double blind study, reported that the association with incision time, incisional blood loss, and postoperative pain reduced in making skin incision with use of electrocautery. ${ }^{4}$ Modern electrosurgical units capable of delivering pure sinusoidal currents have evolved a change in this concept. The advantages are rapid hemostasis, faster dissection, and a reduced overall operative blood loss. ${ }^{5}$ Majority of studies had compared electro cautery and scalpel incision in terms of wound infection, postoperative pain, blood loss, duration of healing and postoperative wound complication in only selected groups of patients with the exclusion of patients with medical co-morbidities. ${ }^{6}$ These studies showed that electric diathermy technique is more effective and beneficial than scalpel. But still most surgeons are not favouring electric diathermy.

The present study was under taken on a group of 105 patients with a view to substantiate the findings of previous studies particularly to confirm the influence of these two techniques of making incisions on bleeding, duration of incision, postoperative pain, wound healing, hospital stay and cosmetic appearance of the scar.

\section{Material \& Methods}

After obtaining the clearance from ethical committee, 105 patients in the age group of 20-60 years who underwent abdominal surgery, were included in the study after obtaining informed and written consent. Patients with Diabetes, heart disease, malignancy, haematological disorders, history of drug abuse or chronic debilitating disease and not consenting to participate in the study, were excluded. Patients were divided into 3 groups with 35 patients in each group: Group-A: Patients in whom incision was made by sharp needle electrode; Group-B: Patients in whom incision to reticular dermis was given with scalpel blade and further incision to the peritoneum with sharp needle electrode Group-C: Patients in whom incision was made by conventional scalpel. All the operations were carried out under general anaesthesia with standard premedication and preparation. Prophylactic antibiotic cover (Ceftriaxone) was given to all the patients. Right subcostal approach was used in all the patients. Duration of incision was recorded as the time interval from beginning of skin incision to opening of peritoneum. Closure of Wound was accomplished by using continuous Vicryl (Coated Polygactin 910 Violet) No. 1 for peritoneum and posterior rectus sheath as well as the anterior rectus 
sheath. Skin was closed by interrupted silk No. 1 mattress sutures.

Incision blood loss was assessed as Minimalonly few small bleeder which were controlled easily with forceps and no need for mopping with sponge. Moderate- some large bleeders in addition to small bleeders, controlled with forceps and by pressure with sponge gauze but with some difficulty. In this type of bleeding less than 50\% of sponge was wet during mopping. Severe- when the bleeding was to such as extent that it was difficult to be controlled by pressure and sponge hence cauterization or ligation with catgut was done. In this type of bleeding more than $50 \%$ of sponge was wet during mopping.

In the post-operative period, analgesic (Diclofenac Sodium) was used on demand and the frequency of injection used was taken as one of the indices of severity of pain. Patients were also interviewed 24 hours after operation for subjective pain score. A 4-point ordered category scale (no pain $=0$; mild pain $=1$; moderate pain $=2$; severe pain=3) was used for assessing the severity of pain in all patients. All the wounds were examined on 3rd postoperative day for degree of healing (signs of inflammation).The sutures were removed between 8th to 10th post-operative days depending upon degree of healing of the wound. Post-operative wound complication (edema, serous discharge, pus discharge, infection, gaping) and hospital stay were also recorded.

Patients were followed up in the out patients clinic for assessment of resultant scar on day 15th, 1 month and 6 month from the date of operation. The cosmetic appearance of scar was graded as excellent, fair, poor. The scar which were in line with the surrounding skin were graded as excellent, those with elevation and moderate fibrosis as fair and those with excessive fibrosis, elevation and ugly appearance as poor.

\section{Statistical Analysis}

Data was analyzed using Statistical Package for Social Sciences, version 23 (SPSS Inc., Chicago, IL). Results for continuous variables are presented as mean \pm standard deviation, whereas results for categorical variables are presented as number (percentage).The results were finally analyzed and compared statistically using t-test, Chi-square test. The level $P<0.05$ was considered as the cutoff value or significance or considered statistically significant.

\section{Results}

The variation in age $(\mathrm{P}=0.976)$ and gender $(\mathrm{P}=0.73)$ distribution among the patients population of three groups were statistically not significant.

Table No.01: Body mass index of patients

\begin{tabular}{|c|c|c|c|c|}
\hline BMI & Group A $(\mathbf{N}=35)$ & Group B $(\mathrm{N}=35)$ & Group C $(\mathbf{N}=35)$ & Significance \\
\hline$<18 \mathrm{~kg} / \mathrm{m}^{2}$ & $2(5.7)$ & $1(2.9)$ & $1(2.9)$ & \multirow{3}{*}{$\begin{array}{c}X^{2}=1.002 \\
P \text { value }=0.909\end{array}$} \\
\hline $19-25 \mathrm{~kg} / \mathrm{m}^{2}$ & $26(74.3)$ & $29(82.9)$ & $28(80.0)$ & \\
\hline$>25 \mathrm{~kg} / \mathrm{m}^{2}$ & $7(20.0)$ & $5(14.3)$ & $6(17.1)$ & \\
\hline
\end{tabular}

The variation in the Body mass index among patient population of the three groups was not statistically significant as $\mathrm{P}=0.909$.

Table No.02: Mean Hemoglobin status of Patients

\begin{tabular}{|l|c|c|c|c|}
\hline Hb & Group A $(\mathbf{N}=35)$ & Group B $(\mathbf{N = 3 5})$ & Group C $(\mathbf{N = 3 5})$ & P value \\
\hline $\begin{array}{l}\text { Haemoglobin } \\
\text { (gm/dl) }\end{array}$ & $11.4 \pm 3.2$ & $12.4 \pm 2.8$ & $12.2 \pm 2.3$ & 0.018 \\
\hline
\end{tabular}

The difference in the Hemoglobin status between the patients of groups A, B \& B,C were statistically significant as $\mathrm{P}=0.018$. 
Table No.03: Incisional Bleeding characteristics of the patients

\begin{tabular}{|c|c|c|c|c|c|}
\hline Bleeding & Group A & Group B & Group C & Total & Significance \\
\hline Minimal & $31(88.6)$ & $24(68.6)$ & $26(74.3)$ & $81(77.1)$ & \multirow{2}{*}{$\mathrm{X}^{2}=4.213$} \\
\cline { 1 - 4 } Moderate & $4(11.4)$ & $11(31.4)$ & $9(25.7)$ & $24(22.9)$ & P value $=0.377$ \\
\hline Severe & $0(0.0)$ & $0(0.0)$ & $0(0.0)$ & $0(0.0)$ & \\
\hline
\end{tabular}

The variation in the bleeding characteristics of the three groups of patients during the course of incision were not statistically significant as $\mathrm{P}=0.377$.

Table No.04: The wound status of the patients on $3^{\text {rd }}$ day of incision

\begin{tabular}{|c|c|c|c|c|c|}
\hline & Group A & Group B & Group C & Total & Significance \\
\hline Dry \& Healthy & $19(54.3)$ & $31(88.6)$ & $34(97.1)$ & $84(80.0)$ & \multirow{2}{*}{$\begin{array}{c}X^{2}=22.5 \\
P \text { value }=<0.001\end{array}$} \\
\hline Inflammed & $16(45.7)$ & $4(11.4)$ & $1(2.9)$ & $21(20.0)$ & \\
\hline
\end{tabular}

The variation in the wound status parameters of the three groups of patients on 3rd day of incision were statistically significant as $\mathrm{P}=<0.001$.

Table No.05: Wound status of the patients on $8^{\text {th }}$ day of incision

\begin{tabular}{|c|c|c|c|c|c|}
\hline & Group A & Group B & Group C & Total & Significance \\
\hline Oedematous & $3(8.6)$ & $1(2.9)$ & $0(0.0)$ & $4(3.8)$ & \multirow{6}{*}{$\begin{array}{c}X^{2}=13.12 \\
P \text { value }=0.217\end{array}$} \\
\hline Serous Discharge & $6(17.1)$ & $9(25.7)$ & $7(20.0)$ & $22(21.0)$ & \\
\hline Pus Discharge & $5(14.3)$ & $3(8.6)$ & $1(2.9)$ & $9(8.6)$ & \\
\hline Dry \& Healthy & $13(37.1)$ & $17(48.6)$ & $24(68.6)$ & $54(51.4)$ & \\
\hline Gaping & $5(14.3)$ & 4 (11.4) & $2(5.7)$ & $11(10.5)$ & \\
\hline Infection & $3(8.6)$ & $1(2.9)$ & $1(2.9)$ & $5(4.8)$ & \\
\hline
\end{tabular}

The variation in the post-operative complications and wound status parameters of the three groups of patients on $8^{\text {th }}$ day of operation were not statistically significant as $\mathrm{P}=0.217$.

Table No.6: Period of Hospital stay of patients

\begin{tabular}{|c|c|c|c|c|c|}
\hline & Group A & Group B & Group C & Total & Significance \\
\hline 5-10 days & $23(65.7)$ & $26(74.3)$ & $31(88.6)$ & $80(76.2)$ & \multirow{2}{*}{$X^{2}=5.145$} \\
\cline { 1 - 5 } 11-15 days & $12(34.3)$ & $9(25.7)$ & $4(11.4)$ & $25(23.8)$ & \multirow{2}{*}{ P value $=0.076$} \\
\cline { 1 - 4 } Total & $35(100.0)$ & $35(100.0)$ & $35(100.0)$ & $105(100.0)$ & \\
\cline { 1 - 5 } Mean \pm SD & $9.8 \pm 2.5$ & $8.6 \pm 2.3$ & $8.2 \pm 1.9$ & & \\
\hline
\end{tabular}

The difference in the period of discharge of patients of different groups, from the Hospital was not statistically significant $P$ value $=0.076$.

Table No.7: Cosmetic appearance of scars after 3 months of discharge

\begin{tabular}{|c|c|c|c|c|c|}
\hline & Group A & Group B & Group C & Total & Significance \\
\hline Excellent & $20(57.1)$ & $23(65.7)$ & $27(77.1)$ & $70(66.7)$ & \multirow{4}{*}{$\begin{array}{c}X^{2}=4.68 \\
P \text { value }=0.321\end{array}$} \\
\hline Fair & $6(17.1)$ & $7(20.0)$ & $5(14.3)$ & $18(17.1)$ & \\
\hline Poor & $9(25.7)$ & $5(14.3)$ & $3(8.6)$ & $17(16.2)$ & \\
\hline Total & $35(100.0)$ & $35(100.0)$ & $35(100.0)$ & $105(100.0)$ & \\
\hline
\end{tabular}

The difference in Cosmetic appearance of scars among the patients of the three groups was not statistically significant $P$ value $=0.321$.

\section{Discussion}

Previous studies have compared diathermy and scalpel incisions in terms of incision time, blood loss, early post-operative pain and post-operative wound infection rates. ${ }^{7}$ This study has focused on diathermy incisions in elective surgical cases exclusively so as to figure out the post-operative wound infection rate.

As far as bleeding during Incision, we noted in our study that in group A, 88.6\% (31) patients had minimal bleeding and $11.4 \%$ (4) had moderate while in group B and C, 68.6\%(24) and $74.3 \%$ (26) patients had minimal bleeding and $31.4 \%(11)$ 
\& $25.7 \%$ (9) patients have moderate bleeding respectively. So it is clear that there was less bleeding in group A. These findings were similar to study done by Mohd. Amin Mir et $\mathrm{al}^{8}$ who made observation on 50 patients in the each group where the incisional bleeding was significantly less in group A as compared to group B and group C. This time the difference was statistically non significant $(p>0.05)$. Ly et al in their systemic review and meta-analysis of fourteen randomized trials comprising of 2541 patients (1267 undergoing abdominal wall incision by cutting diathermy and 1274 by scalpel), found that diathermy may offer significant advantages in many variables including, operative blood loss, incision time and postoperative pain. They noticed significantly reduced amounts of blood loss (mean difference of $0.72 \mathrm{ml} / \mathrm{cm} 2(\mathrm{P}<0.001)$ and shorter incision time (mean difference of 36 seconds; $\mathrm{P}<0.001$ ) with diathermy incisions as compared to scalpel incisions. ${ }^{9}$

In our study, we also noted that $45.7 \%$ (16) of patients have inflamed wound on 3rd day in group $A$ and $11.4 \%$ (4) and 2.9\% (1) of patients in group $\mathrm{B}$ and $\mathrm{C}$ respectively. Thus, it is clear that inflammatory wounds are in greater number of patients on 3rd day in-group A in comparison to B and $\mathrm{C}$. This time the difference is statistically significant $(\mathrm{p}<0.001)$. In our opinion the reason for this increased inflammation in group A on 3rd day is that the electric diathermy causes charring of skin tissue which results in accumulation of a vascular necrotic debris. This debris acts like a foreign body and cause increase in inflammation. In our study, we also noted that Wound Complications On $8^{\text {th }}$ Day, there was edema in $8.6 \%$ (3), serous discharge in $17.1 \%(6)$, pus discharge in $14.3 \%$ (5), gaping in $14.3 \%$ (5) and infection in $8.6 \%$ (3) of patients in group A. In group B $2.9 \%$ (1) patients had edema, 25.7\% (9) had serous discharge, $4 \%$ (2) pus discharge, $8.6 \%$ (3), gaping $2.9 \%$ (1) patients had infection. In group C, we had serous discharge in $20 \%$ (7), pus discharge in $2.9 \%$ (1), gaping in $5.7 \%$ (2) and Infection in $2.9 \%$ (1). Thus it is clear that in group
$\mathrm{C}$ there are less postoperative complications. The difference is statistically non significant ( $>00.001)$. The reason behind the greater number of wound complication in group A and B is that the electro diathermy causes tissue necrosis in addition to division of tissue. There is formation of a vascular necrotic material, which acts, as an inflammatory agent and leads to increase in inflammation. When there is increased inflammation there are more chances of seroma, sepsis and even wound gaping because of poor wound healing.. Similarly, Galal AN in 2007 noted the similar findings in 50 patients and stated that post-operative complications were insignificant in either group. ${ }^{10}$ Groot et al. studied wound infection rate in cases of abdominal or thoracic wounds and compared the electrocautery and steel scalpel. They found that electrocautery does not increase the wound infection rate.

The correlation between these groups shows that there is less hospital stay in group $\mathrm{C}$ as compared to group A and B. In group C $88.6 \%$ (31) and in group B $74.3 \%$ (26) of patients were discharged within 10 days, but in group A only $65.7 \%$ (23) were discharged within 10 days. This time difference is statistically non-significant ( $p>0.01)$. The reason is clear that the healing is poor in group $\mathrm{A}$ and $\mathrm{B}$, and there are more postoperative complications which lead to increased hospital stay. These findings were similar to study done by Mohd. Amin Mir et alError! Bookmark not defined. where hospital stay was significantly less in group C compared to group A and group B. This is possible reason for non-significant data can be due to small sample size of present study. Patil VB et al found inconsistent data from our study where mean hospital stay was $10.22(\mathrm{SD} \pm 4.11)$ days in group Scalpel and $9.33(\mathrm{SD} \pm 2.58)$ days among group Electrocautery patients but the difference was not statistically significant. ${ }^{11}$

It was observed that in group A $57.1 \%$ (20) of patients had excellent scar, in group B $65.7 \%$ (23) and in group C $77.1 \%$ (27). In group A $17.1 \%$ (6) had fair scars, in group B $20 \%$ (7) and in group C $14.3 \%$ (5). Whereas $25.7 \%$ (9) had poor scar in 
group A, in group B $14.3 \%$ (5) and $8.6 \%$ (3) in group $\mathrm{C}$ had poor scar. The above results of correlated statistically are insignificant. Lawrenson and Stephens ${ }^{12}$ also observed some delay in healing following electro surgery but no difference was apparent after the first month. But Peterso, Dixon and Watkin, Nisar $\mathrm{AH}$ et $\mathrm{al}^{13}$ showed that electro surgery produces cosmetically better scar than scalpel blade. If the poor scars were compared between group A and group C then the difference is statistically non-significantly [p>0.05]. In our opinion the greater number of poor scar in group A as compared to group $\mathrm{C}$ is because of greater number of wound complications (infection, wound gaping etc.) in group A.

\section{Conclusion}

On the basis of this study, it is suggested that scalpel blade is superior to electrodiathermy for making surgical incisions. But electro diathermy can be used safely in those cases were conservation of blood is important.

\section{References}

1. Glover JL, Bendick PJ, Link WJ. The use of thermal knives in surgery: electro surgery, lasers, plasma scalpel. Current Problems in Surgery 1978; 15: 1-78

2. Soderstrom R. Principles of electrosurgery as applied to gynaecology. In: Rock JA, Jones HW III editor(s). TeLinde's Operative Gynecology. 9th Ed. Philadelphia: Lippincott Williams \& Wilkins; 2003:291-308

3. Dixon AR and Watkin DFL. Electrosurgical skin incision versus conventional scalpel: a prospective trial. JR Coll Surg Edimb 1990;35: 299-301.

4. Ayandipo OO, Afuwape OO, Irabor D, Oluwatosin OM, Odigie V. Diathermy versus Scalpel Incision in a Heterogeneous Cohort of General Surgery Patients in a Nigerian Teaching Hospital. Nigerian Journal of Surgery: Official Publication of the Nigerian
Surgical Research Society. 2015;21(1):43-47. doi:10.4103/1117-6806.153193.

5. Chalya PL, Mchembe MD, Mabula JB, Gilyoma JM. Diathermy versus scalpel incision in elective midline laparotomy: A prospective randomized controlled clinical study. East and Cent. Afr JSurg 2013;18:71-7

6. Arsalan S, Muhammad F, Athar AS, Sohail R. Elective midline laparotomy; comparison of diathermy and scalpel incisions. Prof Med J. 2011;18:106-11.

7. Kearns SR, Connoly EM, McNally S, McNamara DA, Deasy J. Randomized clinical trial of diathermy versus scalpel incision in elective midline laparotomy. $\mathrm{Br} \quad \mathrm{J}$ Surg 2001;88:41-4.

8. Mohd. Amin Mir, M. Nadeem Khan, Iqbal Aziz, Anis Ismail. Randomized comparative study of electro surgical and conventional scalpel incisions in general surgery. Surgery. 2010;20(25):15-22.

9. Ly J, Mittal A, Windsor J. Systematic review and meta-analysis of cutting diathermy versus scalpel for skin incision. $\mathrm{Br} \mathrm{J}$ Surg. 2012;99(5):613-20.

10. Abul Nagah G, Tarek EF, Lotfy H, Shehab W, Tarek A. Comparative study between using harmonic scalpel and electrocautery in modified radical mastectomy. Egyptian Journal of Surgery 2007;26:176-80.

11. Patil VB, Mule VD, Raval RM, Kulkarni AA. Observational study of scalpel versus electrocautery for subcutaneous incision in elective gynaecological surgeries.Int J Reprod Contracept Obstet Gynecol 2017;6:950-4.

12. Keven B, Lawrenson and Fredericro Stephen's. The use of electrocuting and electrocoagulation in surger. Aust NZ J Surg 1970; 39: 417-421.

13. Nisar AH Chowdri, Nazir AH Wani, Akhtar AH Ganie, Sameer Hassan Naqash, GH Qadir Peer, Khursheed Alam Wani. Prospective randomized comparative study of electro surgical and conventinal scalpel incisions in general surgery. IJS 2001; 63(4): 308-311. 